\title{
An Econometric Analysis of the Influence of the Advocate General on the Court of Justice of the European Union
}

\author{
Carlos Arrebola, * Ana Júlia Maurício** and Héctor Jiménez Portilla***
}

\begin{abstract}
This article contributes to a more comprehensive understanding of the role of the Advocate General in the makeup of the Court of Justice of the European Union. The article measures the influence of the Advocate General on the judgments of the Court of Justice through an econometric study using a probit model with data from annulment procedures of the last twenty years (1994-2014). Despite the acknowledged limitations in establishing the influence of the Advocate General on the case law of the Court of Justice via a quantitative analysis, the regression models used in this article give a statistically significant measure of such influence, improving previous attempts in the literature. The findings suggest that the Court of Justice is approximately 67 per cent more likely to annul an act (or part of it) if the Advocate General advises the Court to annul than if it advises the Court to dismiss the case or declare it inadmissible. These results raise several questions as regards judicial independence and the relevance of the figure of the Advocate General, providing a grounded basis for future discussions and judicial reform.
\end{abstract}

\section{Keywords}

European Union, Court of Justice of the European Union, Advocate General, Influence, Econometrics

* PhD Candidate at the Faculty of Law of the University of Cambridge.

** PhD Candidate at the Faculty of Law of the University of Cambridge.

*** Development Economist and Overseas Development Institute Fellow at the Ministry of Health in Ethiopia.

The authors would like to thank Advocate General Eleanor Sharpston, Dr Albertina AlborsLlorens and Professor Kenneth Armstrong for the elucidating discussions on this topic. The authors would also like to thank Professor Eleanor Spaventa for the thoughtful comments on a previous version of this article, as well as Professor Robert Schütze, the participants at the Durham-Cambridge Doctoral Workshop in EU Law-'Igniting European Union Law: Frameworks for the Future' for the helpful discussion, and the anonymous peer reviewers of the CJICL. All errors remain ours. The database and STATA file with the econometric analysis used in this study can be accessed via email request to Héctor Jiménez Portilla: <hectorjp@ ymail.com>. 


\section{Introduction}

This article attempts to measure the influence of the Advocate General on the judgments of the Court of Justice of the European Union (the Court of Justice or the Court) innovatively using an econometric model to expand the academic literature on this topic and to inform the debate on the role of the Advocate General. The role of the Advocate General is to assist the Court in some of the cases presented before it by delivering reasoned submissions, which are known as opinions. ${ }^{1}$ These opinions are not binding on the Court of Justice. Nevertheless, scholars often assume that these opinions influence the final decisions made by the Court. $^{2}$ In reality, however, the fact that the deliberations of the Court are secret makes it difficult to test this assumption. ${ }^{3}$

Some authors have tried to measure the influence of the Advocates General in the development of the case law of the Court of Justice by using descriptive statistics. ${ }^{4}$ However, such statistics merely identify the frequency with which the opinions of the Advocates Generals (AG opinion(s)) and the decisions of the Court of Justice coincide for a particular sample. Although frequency may indicate correlation, it cannot determine causality. ${ }^{5}$ Moreover, these works do not account for the influence that other variables have in the Court's decisions. There are two

1 Consolidated Version of the Treaty on European Union [2012] OJ C326/13 (TEU) art 19(2); Consolidated Version of the Treaty on the Functioning of the European Union [2012] OJ C326/47 (TFEU) art 252.

2 See Section 2 of this paper.

3 Protocol (No 3) on the Statute of the Court of Justice of the European Union [2012] OJ C326/13 (CJEU Statute) arts 2, 35.

4 Alan A Dashwood, 'The Advocate General in the Court of Justice of the European Communities' (1982) 2 LS 202; Takis Tridimas, 'The Role of the Advocate General in the Development of Community Law: Some Reflections' (1997) 34 CML Rev 1349; Kamiel Mortelmans, 'The Court Under the Influence of its Advocates General: An Analysis of the Case Law on the Functioning of the Internal Market' (2005) 24 YB Eur L 127; Cyril Ritter, 'A New Look at the Role and Impact of Advocates-General-Collectively and Individually' (2006) 12 Columbia J Eur L 751; Adam Lazowski, 'Advocates General and Grand Chamber Cases: Assistance with the Touch of Substitution' (2012) 14 Cambridge YB Eur L Studies 635; Roman Zakharenko, 'Invisible Influence? The Role of the Advocate General in the European Court of Justice on the Development of Community Law' (University Honors in International Studies, 2012) <http://aladinrc.wrlc.org/bitstream/handle/1961/10724/Zakharenko, Roman - Spring 12.pdf> accessed 20 February 2015.

5 Brian Haig, 'Spurious Correlation' in Neil J Salkind (ed), Encyclopedia of Measurement and Statistics (SAGE 2007). 
studies, though, which had a different goal but also carried out an econometric analysis and used the AG opinion as a control variable, reaching a similar conclusion to ours. ${ }^{6}$ Although these studies provide interesting information regarding the influence of the AG opinion on the Court, the authors were unable to determine whether their findings were due to the presence of the AG opinion. In this article, we have undertaken an econometric analysis that builds on the latter studies, and which aims to overcome the shortcomings of the existing literature specifically directed at measuring the influence of the Advocates General on the judgments of the Court of Justice. Aiming to explore the correlation and causation between the AG opinions and the Court's decisions, we have conducted an econometric study using a probit model with data from annulment procedures of the last twenty years (1994-2014). We have considered the AG opinion variable, as well as other variables that might also influence the Court of Justice's decisions. Our findings are statistically significant. In particular, the average marginal effects measure for our sample suggests that the Court of Justice is approximately 67 per cent more likely to annul an act (or part of it) if the Advocate General advises the Court to annul than if it advises the Court to dismiss the case or declare it inadmissible.

Although it is acknowledged that using a quantitative analysis to establish the influence of the Advocate General on the case law of the Court of Justice has limitations, we believe that a carefully designed econometric study will contribute to a more comprehensive understanding of the role of the Advocate General. This article is organised in the following manner: Section 2 elaborates on the existing literature on this topic, summarising the studies conducted and their findings, and identifies the original contribution of this study to the literature. Section 3 describes and justifies the chosen methodology: it explains the shortcomings of descriptive statistics, and the adequacy of using regressions, namely a probit model, to provide a more accurate measure of the influence of the AG opinions on the judgments of the Court of Justice. Section 4 explains and analyses the results, showing that our probit model is robust and a reliable predictor of the behaviour of the Court of Justice in actions for annulment. Having established the influence of the Advocate General on the Court of Justice, Section 5 explores some of the issues raised. It 
raises the implications that this influence might have for the independence of the Court. More generally, this article aims to contribute to a more informed debate on the role and future of the figure of the Advocate General.

\section{Literature Review}

According to the Treaties, the Court of Justice of the European Union 'shall be assisted by Advocates-General.' Advocates General must act 'with complete impartiality and independence. 8 The Advocate General's duty is 'to make, in open court, reasoned submissions on cases which (...) require his involvement', 'in order to assist the (...) Court in the performance of its task.' The literature has described the assistance of the Advocates General as including the following functions: providing assistance to the Court of Justice with the preparation of a case; proposing solutions to cases before the Court of Justice; providing 'legal grounds to justify that solution, in particular, relating it to the existing case law'; opining 'on such points of law incidental to the case'; and making 'a critical assessment of the case law or comment[ing] on the development of the law in the area in issue..

The reasoned submissions of the Advocates General, known as opinions, might play a role in the outcome of the cases before the Court of Justice. Put differently, an opinion may influence the actual decision taken by the Court. However, AG opinions are not binding on the Court of Justice, the Advocates General do not

TEU (n 1) art 19(2); for a comprehensive account of the literature on the Advocate General, see Rosa Greaves, 'Reforming Some Aspects of the Role of Advocates General' in Anthony Arnull and others (eds), A Constitutional Order of States? Essays in EU Law in Honour of Alan Dashwood (Hart Publishing 2011) 162-66.

8 TFEU (n 1) art 252.

9 ibid; CJEU Statute (n 3) art 49.

10 Tridimas (n 4) 1358; see also, eg, Dashwood (n 4); Kirsten Borgsmidt, 'The Advocate General at the European Court of Justice: A Comparative Study' (1988) 13 EL Rev 106; Martin Vranken, 'The Role of the Advocate General in the Law-Making Process of the European Community' (1996) 25 Anglo-American L Rev 39; Ruiz-Jarabo Colomer and López Escudero, 'The Institution of Advocate General at the Court of Justice of the European Communities' in Rodriguez Iglesias and others (eds), Mélanges en Hommage à Fernand Schockweiler (Nomos 1999); Francis G Jacobs, 'Advocates General and Judges in the European Court of Justice: Some Personal Reflections' in David O'Keeffe and Antonio Bavasso (eds), Judicial Review in European Union Law, vol 1 (Kluwer Law International 2000); Philippe Léger, 'Law in the European Union: The Role of the Advocate General' (2004) 10 J Legislative Studies 1; Mortelmans (n 4); Ritter (n 4); Noreen Burrows and Rosa Greaves, The Advocate General and EC Law (OUP 2007). 
take part in the Court's deliberations-which are secret-and the Court's decisions do not usually give an account of the various elements that influenced them. ${ }^{11}$ This has caused difficulties in measuring the influence of the AG opinions on the Court's case law. Nevertheless, evaluating the relevance of this mechanism in the makeup of the Court of Justice of the European Union and its case law has frequently been attempted by scholars. This level of attention is reflective of the fact that the issue is open for discussion and warrants attention, since the influence of AG opinions could affect the legitimacy and independence of the Court of Justice.

Influence generally means the capacity to have an effect on someone or something. The discourse of influence has been commonly used to study how courts respond to external factors, including the executive power and war, ${ }^{12}$ and threats of executive noncompliance and legislative override. ${ }^{13}$ It has also been used in the European legal literature in the context of the relationship between the AG opinions and the decisions of the Court of Justice. In this ambit, the concept of influence has been given different meanings, which have led scholars to distinct conclusions. For instance, influence has been interpreted to mean 'the power of the Advocate General to persuade the Court' or, more generally, the significance of the AG opinions in the decision-making of the Court of Justice. ${ }^{14}$ Despite the precise definition of influence, it is widely accepted that the AG opinions have an effect on the decision-making of the Court of Justice. ${ }^{15}$ However, it is discussed whether it

11 CJEU Statute (n 3) arts 2, 35.

12 Tom S Clark, 'Judicial Decision Making During Wartime' (2006) 3 J Empirical L Studies 397.

13 Carrubba, Gabel and Hankla (n 6).

14 Albertina Albors-Llorens, 'Securing Trust in the Court of Justice of the EU: The Influence of the Advocates General' (2012) 14 Cambridge YB Eur L Studies 509, 515-16 (emphasis in original).

15 See, mainly, Dashwood (n 4); Vranken (n 10); Tridimas (n 4); Anthony Arnull, The European Union and Its Court of Justice (2nd edn, OUP 2006) 15; Colomer and Escudero (n 10); Jacobs (n 10); Léger (n 10); Mortelmans (n 4); Ritter (n 4); Eleanor Sharpston, 'The Changing Role of the Advocate General' in Anthony Arnull, Piet Eeckhout and Takis Tridimas (eds), Continuity and Change in EU Law: Essays in Honour of Sir Francis Jacobs (OUP 2008); Greaves (n 7); Iyiola Solanke, “Stop the ECJ?": An Empirical Analysis of Activism at the Court' (2011) 17 Eur LJ 764; Albors-Llorens (n 14); Michal Bobek, 'A Fourth in the Court: Why Are There Advocates General in the Court of Justice?' (2012) 14 Cambridge YB Eur L Studies 529; Laure ClémentWilz, 'The Advocate General: A Key Actor of the Court of Justice of the European Union' (2012) 14 Cambridge YB Eur L Studies 587; Lazowski (n 4); Iyiola Solanke, 'The Advocate General: Assisting the CJEU of Article 13 TEU to Secure Trust and Democracy' (2012) 14 Cambridge YB Eur L Studies 697; Sophie Turenne, 'Advocate Generals' Opinions or Separate Opinions? Judicial Engagement in the CJEU' (2012) 14 Cambridge YB Eur L Studies 723; Zakharenko (n 4). 
is possible to evaluate the effect of the AG opinions in the case law of the Court of Justice, namely, quantitatively.

Dashwood affirmed that the 'received wisdom is that the Court follows the Advocate General in about 70 per cent of cases', although his experience at the Court of Justice led him to believe that the percentage was lower. ${ }^{16}$ However, Dashwood did not provide information as to the methodology used to obtain the figure he advanced. Tridimas was one of the first to attempt measuring the influence of the AG opinions. ${ }^{17}$ He adopted a 'material criterion', ie, 'the proportion of cases within a given period in which the Court followed the opinion', using a six-month period in 1996, and looking at any type of procedure. Tridimas concluded that the opinions were followed in 88 per cent of the cases. ${ }^{18} \mathrm{He}$ explored another possible criterionidentifying the main developments in the Court's case law and verifying if the AG opinions were followed in those cases-but did not present any results. ${ }^{19}$ This interesting study could have provided an explanation of Tridimas' understanding of the concept follow to further elucidate the readers of the methodology used.

There have been qualitative and mixed-methods (quantitative and qualitative) studies of the influence of the AG opinions on the Court of Justice. One was conducted by Mortelmans, who focused on the role played by the Advocates General in the case law regarding the functioning of the internal market. ${ }^{20} \mathrm{He}$ resorted to purposive sampling, and then used two approaches to determine whether an opinion had been followed by the Court of Justice. He used a 'direct route', ie, cases in which the Court expressly states that it concurred with the AG opinion, and an 'indirect route, 'comparing the judgment with the Opinion to establish whether or not the Opinion has been embraced. ${ }^{21}$ On the basis of both a quantitative and qualitative analysis, Mortelmans concluded that being followed is only one aspect of having influence. He identified specific periods of time, and stated whether the Court agreed with the views of the Advocates General on a majority of cases, highlighting the useful role of the Advocate General. ${ }^{22}$

17 Tridimas (n 4).

18 ibid 1362.

19 ibid 1363.

20 Mortelmans (n 4).

21 ibid 140.

22 ibid 140-72. 
Ritter also completed a study on this topic, testing the degree of influence of the Advocate General on the decision-making of the Court. ${ }^{23}$ He used a twoyear period (2004-05), analysed cases stemming from all types of procedures, and used two criteria to evaluate if the Court followed the AG opinions. ${ }^{24}$ Ritter identified decisions citing the AG opinion at least once, and decisions citing the AG opinion for each legal issue in question. Interestingly, Ritter also determined which Advocates General were cited more frequently. ${ }^{25}$ Nevertheless, and despite acknowledging that his methodology is a mere 'proxy for the actual number of times when the Court followed the opinion', he simply verified the frequency with which an opinion was cited, providing a ratio of citation to opinions for 2004 and $2005 .^{26}$

Other attempts include Lazowski's purposive sampling and qualitative study of a small number of Grand Chamber preliminary reference procedure cases, where the Court of Justice concurred with or ignored the Advocate General, in order to 'demonstrate the usefulness of the opinions of those Advocates General who lay down the foundations for the Court of Justice and offer true assistance', in some cases 'with the touch of substitution. ${ }^{27}$ Another quantitative and qualitative analysis was conducted by Zakharenko, who measured the influence of the Advocates General via an investigation of infringement procedure cases decided between $1961-77 .{ }^{28}$ Providing an account of the methodology followed-ie, verifying if the Court ruled in the same way as proposed by the Advocate General-the author claimed that the Court followed the AG opinions in 91 per cent of the infringement procedure cases during the selected time period. ${ }^{29}$ Furthermore, Zakharenko also concluded that in 76.5 per cent of the cases the 'wording and phrasing used in the concluding statements were identical. ${ }^{30}$

Some academics have criticised these interesting contributions because it is not simple to ascertain whether the Court of Justice followed the AG opinion in a given case. As mentioned, the deliberations of the Court are secret, and the Court 
does not systematically cite the AG opinion, even if it follows it. ${ }^{31}$ In fact, the Court rarely states expressly that it has followed the AG opinion. In the cases where the opinion is mentioned, the Court usually refers to it merely as evidence offered to support one of its conclusions. ${ }^{32}$ Furthermore,

The opinion may have been followed to a greater or lesser extent. The Court may reach the same result but on the basis of different reasoning and, in some cases, it may not be obvious which parts of the advocate general's reasoning the Court has endorsed. $^{33}$

In fact, some scholars feel that those difficulties render it impossible to measure the 'power of the Advocate General to persuade the Court. ${ }^{34}$ They justify it on the basis that

Even if an exhaustive statistical analysis was carried out of the number of cases where the Court 'followed' the Advocate General, this would not be accurate because in cases where the same conclusion is reached by the Court, the reasoning might well be different. Such a view of the influence of the Advocate General would be, at any rate, extremely narrow-minded and confined to the analysis of perceived results instead of encompassing the full extent of the contribution of the Advocate General to the development of EU law. ${ }^{35}$

This view mirrors that of Tridimas, who criticised the two criteria of result he advanced, since 'the influence of the advocate general goes beyond his contribution to the individual case. ${ }^{36}$ Instead of determining the influence of an AG opinion on an individual case, Tridimas was more interested in the 'dialectical interplay between opinions and judgments', trying to evaluate the influence of the Advocate General on the development of European Union (EU) law more broadly. ${ }^{37}$ This seems to be the opinion of this strand of the scholarship, which prefers not to focus

CJEU Statute (n 3) arts 2, 35; see Ritter (n 4) 767; Solanke, “Stop the ECJ?”: An Empirical Analysis of Activism at the Court' (n 15) 769; Albors-Llorens (n 14) 515. Jacobs (n 10) 22; Ritter (n 4) 766; Greaves (n 7) 165-66, 169; Albors-Llorens (n 14) 510-16; Zakharenko (n 4) 29-30. Albors-Llorens (n 14) 515 (emphasis in original). ibid 515-16. 64, 168-70; Solanke, “Stop the ECJ?": An Empirical Analysis of Activism at the Court' (n 15) 771. 
on the influence of the Advocates General on the case law of the Court of Justice, but to look at 'their potential ability to improve the quality of that case law." It is also argued that the AG opinions promote trust in the Court of Justice-trust as the belief that the Court makes the right decisions-which ultimately improves the Court's legitimacy. ${ }^{39}$

We agree that the influence of the Advocate General in the development of the case law of the Court of Justice and, more generally, in the makeup and legitimacy of the Court of Justice cannot be fully evaluated on the basis of a quantitative analysis. Such an endeavour would merit a broader analysis of the figure of the Advocate General, including: its opinions; the influence of its opinions in the case law of the Court of Justice; the clarity offered by the opinions to a fuller understanding of the case law; the sociological impact of having Advocates General for the judges of the Court of Justice, for the other EU and national institutions, and for the individuals of the Member States. Nevertheless, enquiries like ours, quantitatively measuring the effect that an AG opinion has on the Court's solution of a case, are necessary and extremely valuable contributions to a comprehensive understanding of the role and implications of the figure of the Advocate General, and should be carried out in their own right. Furthermore, we feel that the doubts expressed in the literature can be minimised by conducting more refined econometric analysis, such as the probit model used here, which can accurately determine and predict the influence of the AG opinions on the decisions of the Court in relation to other possibly influential variables. The present study provides a methodological improvement over previous contributions that used descriptive statistics, which can only identify the frequency with which the AG opinions and the decisions of the Court of Justice coincide in a determined sample, and cannot account for the influence that other variables have in the Court's decisions.

A quantitative analysis of influence, as the one proposed here, was encouraged by Carrubba, Gabel and Hankla, who carried out thorough econometric analyses in slightly different topics, using the AG opinion as a control variable for their measurement. ${ }^{40}$ One of the studies identified that the AG opinion had a systematic positive influence on the decisions of the Court of Justice in the period of 1987-97,

39 Albors-Llorens (n 14); Alicia Hinarejos, 'Social Legitimacy and the Court of Justice of the EU: Some Reflections on the Role of the Advocate General' (2012) 14 Cambridge YB Eur L Studies 615.

Carrubba, Gabel and Hankla (n 6); Carrubba and Gabel (n 6). 
namely, that the AG opinion 'shifts the likelihood of a pro-plaintiff ruling by 60 percentage points. ${ }^{, 11}$ In a later analysis using data from 1960-99, Carrubba and Gabel indicated that the AG opinions and decisions of the Court of Justice 'coincide on 86 percent of the legal issues', and that the likelihood of a pro-plaintiff decision by the Court increases between 49 per cent and 66 per cent if the opinion of the Advocate General is pro-plaintiff. ${ }^{42}$ However, the probit models designed and used in these studies were not directed at measuring the influence of the AG opinions in the decisions of the Court of Justice. Instead, the 2008 study aimed at estimating the degree to which threats of override and noncompliance influenced judicial decision-making in the Court of Justice, ${ }^{43}$ whereas the 2015 one addressed the issue of government compliance with international law and international courts' rulings, using the Court of Justice as a case study. ${ }^{44}$ In both works, introducing the AG opinion as a variable had the sole objective of controlling for 'the quality of the legal argument. ${ }^{45}$ In fact, its authors expressly acknowledged that they could not determine whether their control variable findings were due to the presence of the AG opinion. ${ }^{46}$ Nevertheless, the authors believed that their preliminary findings regarding the Advocate General control variable were significant, and showed that further research specifically focused on measuring the influence of the AG opinion in the Court of Justice was necessary. ${ }^{47}$

We are, therefore, building on Carrubba, Gabel and Hankla's analyses, having confirmed their findings using a different dataset and regressions, and with a model specifically tailored towards measuring the influence of the Advocate General on the Court of Justice. In sum, we have focused specifically on the Advocate General and used refined econometric tools, with variables that particularly aim at exploring the correlation and causation between the AG opinions and the Court's decisions, isolating this variable from others. The design of our research project and the selected methodology are described and justified in the following section.

41 Carrubba, Gabel and Hankla (n 6) 449.

42 Carrubba and Gabel (n 6) 95, 101-02, 123-24.

43 Carrubba, Gabel and Hankla (n 6) 435-36.

44 Carrubba and Gabel (n 6) 11-15.

45 Carrubba, Gabel and Hankla (n 6) 447-48; similarly, see Carrubba and Gabel (n 6) 86-124.

46 Carrubba, Gabel and Hankla (n 6) 449; similarly, see Carrubba and Gabel (n 6) 95, n 10. In the latter, the authors declare that ' $[\mathrm{d}]$ emonstrating (...) influence is complicated', and that '[f] or [their] purposes, the question is beside the point'. Carrubba, Gabel and Hankla (n 6) 449; see also Carrubba and Gabel (n 6) 95 fn 10. 


\section{Methodology}

The existing literature specifically analysing the relationship between the Advocate General and the Court of Justice only provides a measure for descriptive statistics, as we have explained in the previous section. Descriptive statistics only allow us to explain the correlation between the Advocate General and the Court, but not a potential causal relationship. ${ }^{48}$ For that reason, and building on different studies, ${ }^{49}$ we have designed several regressions that help us obtain a more refined measure of the actual influence of the Advocate General. ${ }^{50}$ In this section, we have focused, firstly, on how causal effects can be explained in particular situations, and why it is adequate to use regressions in this case. Secondly, the variables that have been included in our models are introduced. Finally, this section elaborates on the type of regression chosen, ie, a probit regression.

\subsection{Proving causal effects}

Econometric models have been widely used in applied economic literature to disentangle the causal effects of different factors on the outcomes of specific interventions. ${ }^{51}$ For example, Miguel and Kremer used econometrics to uncover the causal link between deworming students in some villages in Kenya and their academic results. ${ }^{52}$ In this case, the causal link could be understood by the use of randomised controlled trials. Essentially, the authors compared the outcomes of a treatment group and of a control group. The deworming intervention was only applied to the treatment group. Any difference between the two groups could only be attributed to the tested intervention, ie, the deworming policy. All other

48 Haig (n 5).

49 Carrubba, Gabel and Hankla (n 6); Carrubba and Gabel (n 6).

50 A 'regression' can be defined as '[a] tool for numerical data analysis that summarizes the relationship among the variables in a data set as an equation, where the variable of interest, or the dependent variable, is expressed as a function of one or several explanatory variables': John Black, Nigar Hashimzade and Gareth Myles, A Dictionary of Economics (4th edn, OUP 2012) 346.

51 For those interested, the J-PAL website compiles many projects that used econometrics as the tool to uncover causal effects: <www.povertyactionlab.org > accessed 20 January 2015.

52 Edward Miguel and Michael Kremer, 'Worms: Identifying Impacts on Education and Health in the Presence of Treatment Externalities' (2004) 72 Econometrica 159. 
possible known and unknown factors were equivalent across the treatment and control groups due to the randomisation.

Randomised controlled trials are considered the cleanest method to estimate treatment effects as it removes the selection bias. ${ }^{53}$ However, many issues are not suited to a randomised controlled trial approach. In the present study, it is not possible to create a randomised controlled trial to define the causal effect of the AG opinion on the Court of Justice. This would require having the ability to design empirical experiments using the Court of Justice as a laboratory, which is unfeasible in practice. ${ }^{54}$ Even if that were possible, it might not be the best use of the resources of the European judiciary.

For cases that are not amenable to randomised controlled trials, regression estimates can provide a partial solution. ${ }^{55}$ Essentially, by controlling for all the covariates correlated with both participation and outcome, one can find a reliable estimate of the causal effect of interest. ${ }^{56}$ For example, in the study on the effect of deworming, if there was no control group because deworming had been offered to the whole village, families would have self-selected into treatment. Comparing the

53 Esther Duflo, Rachel Glennerster and Michael Kremer, 'Using Randomization in Development Economics Research: A Toolkit' [2007] Development Economics, Discussion Paper No 6059, $7<\mathrm{http} / / /$ scholar.harvard.edu/files/kremer/files/randomization_toolkit_dev_economics.pdf> accessed 21 January 2015.

54 For that to be viable, we would need to have the same case be subject to different AG opinions, and two chambers of the Court ruling independently after each of those opinions. Only then could we compare the rulings of the Court and estimate the causal effect of the AG opinion. This would require deception of two different chambers into thinking they were exclusively ruling the case. Additionally, it would require having the same Advocate General generating two opposing opinions and presenting them in each of the chambers. Alternatively, we could explore the causal effect by submitting the same case to two chambers within the Court, where only one of them would have access to the AG opinion. However, this is still unfeasible since the judges would have to be deceived into thinking that only their chamber was ruling on the case. Even if one succeeded in conducting such unfeasible experiments, there would still be biases that could undermine the conclusions reached. This is because there could be important factors determining the decision of the Court that were independent of the AG opinion and difficult to measure. This could be the case, since similar cases may sometimes lead to different judicial results. Therefore, even if we designed the same case and gave it to two different compositions of the Court under similar conditions, other unknown factors could affect the results, such as judges' prejudices and/or presumptions. For a discussion about the factors that might affect judicial decisions, see Richard A Posner, How Judges Think (HUP 2008). the Evaluation of Training Programs' (1999) 94 J American Statistical Association 1053. ibid. 
outcomes of beneficiaries and non-beneficiaries in that case would be contaminated by selection bias. This is because the families that followed the treatment could also be those who, for example, were more responsible and concerned about their children's prospects. In that case, those children could have done better at school even in the absence of the deworming initiative. Hence, if only considering participation in the deworming programme, one would be overestimating the effect of the deworming pills. To solve this overestimation, a regression that accounted for how responsible the family was and whether the deworming took place could be designed.

For the purposes of the present study-measuring the influence of the AG opinion on the decisions of the Court of Justice-it is not possible to conduct a randomised controlled trial. Therefore, we have decided to estimate regressions including other variables that could potentially be biasing the results if we only looked at what the Advocate General said and whether the Court followed the Advocate General's position. In particular, one of the bias factors is the clarity of the law in a given case. For example, the Court and the Advocate General could reach the same result in a case, not because the Court decided to follow the AG opinion, but because the law was clear on what the outcome should be, and there was no room for different interpretations. Therefore, not accounting for the clarity of the case could overestimate our measure of the influence of the Advocate General.

\subsection{Variables included in the regressions}

Estimating our regression in order to establish the influence of the Advocate General on the Court of Justice, we have collected data from 20 years of actions for annulment procedures before the Court of Justice. ${ }^{57}$ Every case from January 1994 to January 2014 has been included, with the exception of appeals from the General Court and those cases that do not have an AG opinion. We collected a total of 285 observations. For these cases, we have examined the behaviour of the Court and the Advocate General as regards to their decision to annul or not to annul the legal act in question. the Curia database available at the website of the Court of Justice of the European Union: $<$ http://curia.europa.eu/juris/recherche.jsf?language $=$ en\&jur $=\mathrm{C}, \mathrm{T}, \mathrm{F} \& \mathrm{td}=\mathrm{ALL} \#>$ accessed 20 November 2014. We selected the period 1 January 1994 to 31 January 2014 and the procedure action for annulment. 
This means that we have created two dichotomous (also called dummy or binary) variables: ECJannulment and AGannulment. ECJannulment is the one that we have considered as the dependent variable. It takes the value of 1 if the Court decided to annul or partially annul an act, and 0 if it dismissed the case or deemed it inadmissible. AGannulment is the variable that we have considered independent. It takes the value of 1 if the Advocate General issued an opinion recommending the Court to annul or partially annul an act, and 0 if it recommended dismissing the case or declaring it inadmissible.

AGannulment is our covariate of interest, because it is the one used to measure the influence of the Advocate General on the Court of Justice. Henceforth, for the purposes of this article, the term influence means the effect that the AG opinion has on the Court's solution of a case. Influence does not refer to the effect that other elements related to the Advocate General have on the Court, such as gender, nationality, height, age, etc. Neither is it a measurement of the effect of the presence of the Advocate General in the proceedings, as opposed to cases that are solved without Advocate General participation. Influence simply means the effect of the AG opinion on the judgment of the Court of Justice.

This is the reason why we have chosen data from the action for annulment procedure. ${ }^{58}$ Actions for annulment are a commonly used procedure, in which it is possible to measure influence in the mentioned terms. It allows for a fairly clear result, which can be more easily coded, as there are only four possible decisions: declare the action inadmissible; dismiss the action; declare the partial annulment of the legal act; or declare the total annulment of the legal act. ${ }^{59}$ Both the Court and the Advocate General have to provide one of those answers. Therefore, the behaviour of the Court and of the Advocate General can be consistently compared. As a result, we could predict with our regressions if the Court of Justice would change its decision from dismissal or inadmissibility to annulment if the Advocate General changed its decision, ceteris paribus-every other variable that may affect the decision of the Court remaining constant.

This simplicity in coding is not available for other commonly used procedures before the Court of Justice, such as preliminary references, in which it is not

59 Carrubba, Gabel and Hankla (n 6) 440: with a similar objective in mind, these authors accounted for each 'legal issue disposed of by the ECJ when it decided a case' as individual observations in their dataset. 
predictable what the result of a case could be. In preliminary references, even if one could compare the response given by the Court and the Advocate General, the national court may have referred several preliminary questions. The Court and the Advocate General may agree as to the decision regarding some of the questions referred, but disagree as regards others. In such cases, how can one code the AG opinion and the judgment of the Court in a manner that objectively displays whether they agree or disagree? An objective comparison between judgment and opinion in preliminary references is certainly more complicated. ${ }^{60}$ In any case, we acknowledge that neither actions for annulment nor preliminary reference procedures are well suited to objectively define whether the Court of Justice and the Advocate General follow the same legal reasoning. ${ }^{61}$ Although we are unable to account for legal reasoning, we believe that the annulment procedure, with its finite number of possible results, is generally adequate for this study because it allows us to consistently track the results of the opinions and judgments.

Despite the general adequacy of actions for annulment for our study, we have encountered several complexities in coding the variables ECJannulment and AGannulment that should be acknowledged here. First, inadmissibility and dismissal are sometimes used as interchangeable terms, although technically the substance of the case is not analysed in cases of inadmissibility, whilst it is in cases that are dismissed. Similarly, the words partial and total annulment are used with a different meaning depending on the case. Sometimes, partial annulment referred to annulling part of the whole act that had been contested, whereas other times it referred to annulling part of the provisions that the claimant had requested to be annulled.

Due to these complexities, and the fact that the proportion of judgments in the sample that declared a partial annulment was relatively small, we decided to simplify the measurement of our two main variables by creating two binary variables that only account for whether annulment of some kind had been requested. For both total and partial annulment, ECJannulment and AGannulment are equal to 1, otherwise they are equal to 0 . This does not seem to alter the results substantially, and it makes it easier to interpret. In our view, this simplification is justified because the regression still allows us to determine whether a movement towards some kind

60 ibid.

61 Note the concerns expressed in Albors-Llorens (n 14) 515-16. 
of annulment in the AG opinion would influence any movement of such kind in the Court's decision, regardless of the specific type of annulment that is requested.

\subsection{Other independent variables}

As explained above, regression estimates can uncover causal effects if all the variables that affect the regressor of interest and/or the outcome are included. In that spirit, this econometric model includes, as well as AGannulment, other variables in an attempt to control for all the relevant factors underlying a Court's decision. ${ }^{62}$

When constructing an econometric model, a researcher should aim to include the following two groups of covariates. First, all the variables correlated both with the AG opinion and the Court's ruling should be included. Otherwise, our estimators would be flawed due to omitting variable biases. Second, by incorporating other variables that could potentially explain the Court's ruling, the accuracy of the model is improved. In other words, regressors with explanatory power reduce the standard errors of the estimates, and therefore make them more significant. Finally, there is another group of covariates that one should try to avoid. These are variables that are almost completely unrelated to the outcome of interest. Including these could over-dimension our model and increase the standard errors, impairing the significance of our estimates.

In sum, this analysis tries to account for the effect of the AG opinion, as well as that of other variables that would explain the behaviour adopted by the Court (and the Advocate General). This makes the results more reliable, in the sense that not all of the decision of the Court is being attributed to the variable AG opinion. Instead, it provides a more accurate estimate of the actual size of that influence. Thus, we feel that the legal scholarship will be in a better position to discuss whether and/or why the Court of Justice follows the Advocate General, and the present and future meaning of the role of the Advocate General within the Court of Justice. Table 1 below summarises the covariates that have been included alongside AGannulment, and provides a justification for the effect each of the independent variables is trying to capture. ${ }^{63}$ 
Table 1

\begin{tabular}{|c|c|c|}
\hline Group/Topic & Variables & Rationale for inclusion \\
\hline \multirow{4}{*}{ CLAIMANT $^{64}$} & Member State & \multirow{4}{*}{$\begin{array}{l}\text { The group of the variable Claimant controls the } \\
\text { biases related to who requests the annulment. The } \\
\text { logic behind this set of variables comes from the } \\
\text { idea that the Court (and the Advocate General) may } \\
\text { be more inclined to side with EU institutions or } \\
\text { individual claimants than with Member States. This } \\
\text { could be the case because the Court might share a } \\
\text { common goal of furthering European integration } \\
\text { with other institutions, which might not be apparent } \\
\text { in the interventions of the Member States before } \\
\text { the Court of Justice. Therefore, the Court could } \\
\text { subjectively be siding with claimants that share its } \\
\text { vision of the EU. }\end{array}$} \\
\hline & Institution & \\
\hline & Semi-privileged claimant & \\
\hline & $\begin{array}{l}\text { Non-privileged claimant } \\
\text { (natural or legal person) }\end{array}$ & \\
\hline \multirow{12}{*}{$\begin{array}{l}\text { ADVOCATE } \\
\text { GENERAL }^{66}\end{array}$} & Alber & \multirow{12}{*}{$\begin{array}{l}\text { The block of the variables Advocate General } \\
\text { removes the effect related to the identity of the } \\
\text { Advocate General in each case. These binary } \\
\text { variables remove the bias caused by some } \\
\text { Advocates General who are intrinsically more } \\
\text { prone to ask for the annulment of a legal act, and } \\
\text { whose personality or skills make him more capable } \\
\text { of convincing the Court. This interpretation would } \\
\text { include these variables into the category of potential } \\
\text { confounders. Therefore, we are essentially trying to } \\
\text { isolate the effect of the AG opinion on the Court } \\
\text { from the subjectivity involved in each Advocate } \\
\text { General's personality, reputation or ability. }\end{array}$} \\
\hline & Bot & \\
\hline & Cosmas & \\
\hline & Darmon & \\
\hline & Elmer & \\
\hline & Fennelly & \\
\hline & Geelhoed & \\
\hline & Gulmann & \\
\hline & Jaaskinen & \\
\hline & Kokott & \\
\hline & La Pergola & \\
\hline & Leger & \\
\hline
\end{tabular}

This group of variables is formed by four binary variables that take the value 1 if the claimant of the case is that indicated on the name of the variable, and 0 otherwise. See TFEU (n 1) art 263 for a list of possible claimants in actions for annulment; also, to understand what is meant by privileged, semi-privileged, and non-privileged, see, eg, Paul Craig and Gráinne De Búrca, EU Law: Text, Cases, and Materials (5th edn, OUP 2011) 485-518.

65 For clarification purposes, it should be noted that, although currently non-privileged applicants exercise their actions for annulment before the General Court, and our study does not cover appeals from the General Court, there was a period in our sample when non-privileged applicants could exercise this type of actions before the Court of Justice. This competence was only granted to the General Court (the Court of First Instance at the time) by the Council Decision of 8 June 1993 amending Council Decision 88/591/ECSC, EEC, Euratom establishing a Court of First Instance of the European Communities (93/350/ECSC, EEC, Euratom) [1993] OJ L144/21.

This group of variables is formed by 25 binary variables that take the value 1 if the Advocate General of the case is that indicated on the name of the variable, and 0 otherwise. The full list of Advocates General is available in the Curia search form at the website of the Court of Justice: $<$ http://curia.europa.eu/juris/recherche.jsf?language=en\&jur=C,T,F\&td=ALL\#> accessed 20 November 2014. The Advocates General that did not issue any opinion during the period selected in our sample have been excluded. 


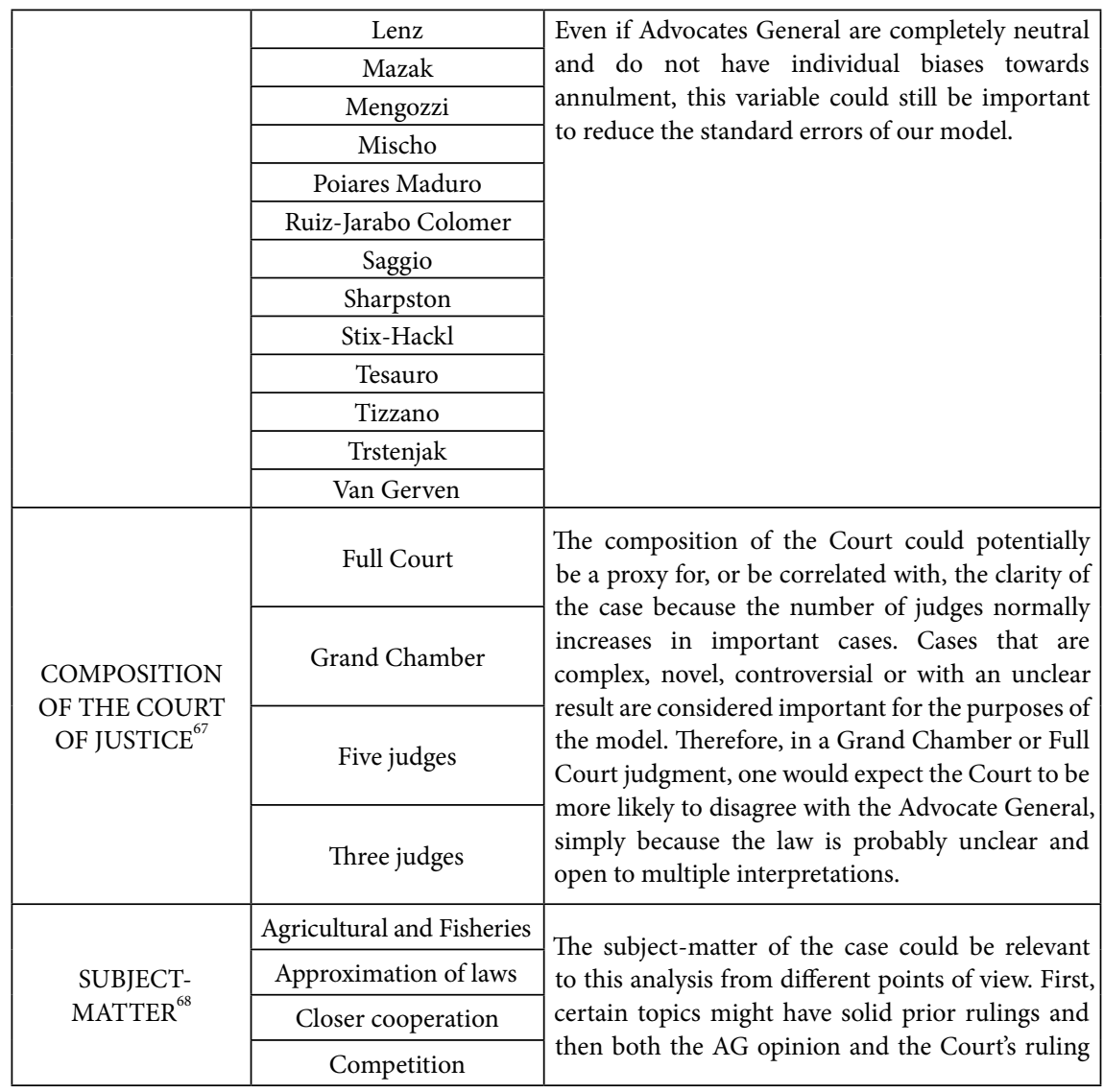

This group of variables is formed by four dummies that take the value 1 if the formation of the Court is that indicated on the name of the variable, and 0 otherwise. The different formations of the Court are explained in CJEU Statute (n 3) art 16; although the number of judges in the Court has changed over time and in some periods of the sample there are not any Grand Chamber judgments, we have limited ourselves to follow the classification made in the Curia database provided in the Court of Justice website: <http://curia.europa.eu/juris/recherche. jsf?language $=$ en\&jur $=$ C,T,F\&td $=$ ALL\# $>$ accessed 20 November 2014. This means that some of the older cases are classified as Full Court despite the fact that the number of judges is less than that of a Grand Chamber in present time. We believe that this does not curtail the validity of using this variable.

68 This group of variables is formed by 26 binary variables that take the value 1 if the subject matter of the case is that indicated on the name of the variable, and 0 otherwise. The full list of subjects is available in the Curia search form at the website of the Court of Justice: $<$ http://curia.europa.eu/juris/recherche.jsf?language=en\&jur=C,T,F\&td=ALL\#> accessed 20 November 2014. The subjects that were not addressed in any case in our sample have been excluded. Sub-classifications of subjects have not been taken into account. 


\begin{tabular}{|c|c|c|}
\hline \multirow{26}{*}{ 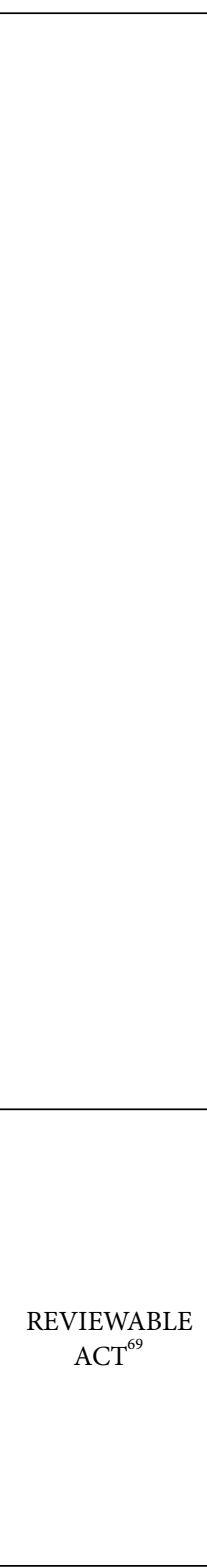 } & $\begin{array}{c}\text { Economic and monetary } \\
\text { policy }\end{array}$ & \\
\hline & $\begin{array}{c}\text { Economic social and } \\
\text { territorial }\end{array}$ & \\
\hline & Energy & \\
\hline & Environment & \\
\hline & European Social Fund & \\
\hline & External relations & \\
\hline & Financial provisions & \\
\hline & Free movement of goods & \\
\hline & Freedom of establishment & \\
\hline & $\begin{array}{c}\text { Freedom of movement } \\
\text { for workers } \\
\end{array}$ & \\
\hline & $\begin{array}{c}\text { Freedom to provide } \\
\text { services }\end{array}$ & \\
\hline & Industrial policy & \\
\hline & Justice and home affairs & \\
\hline & $\begin{array}{c}\text { Overseas countries and } \\
\text { territories }\end{array}$ & \\
\hline & Principles objectives & \\
\hline & \begin{tabular}{|c|} 
Provisions governing the \\
institutions
\end{tabular} & \\
\hline & Social policy & \\
\hline & Social security & \\
\hline & $\begin{array}{c}\text { Staff regulations of } \\
\text { officials }\end{array}$ & \\
\hline & Taxation & \\
\hline & Trans-European networks & \\
\hline & Transport & \\
\hline & Regulation & \multirow{4}{*}{ 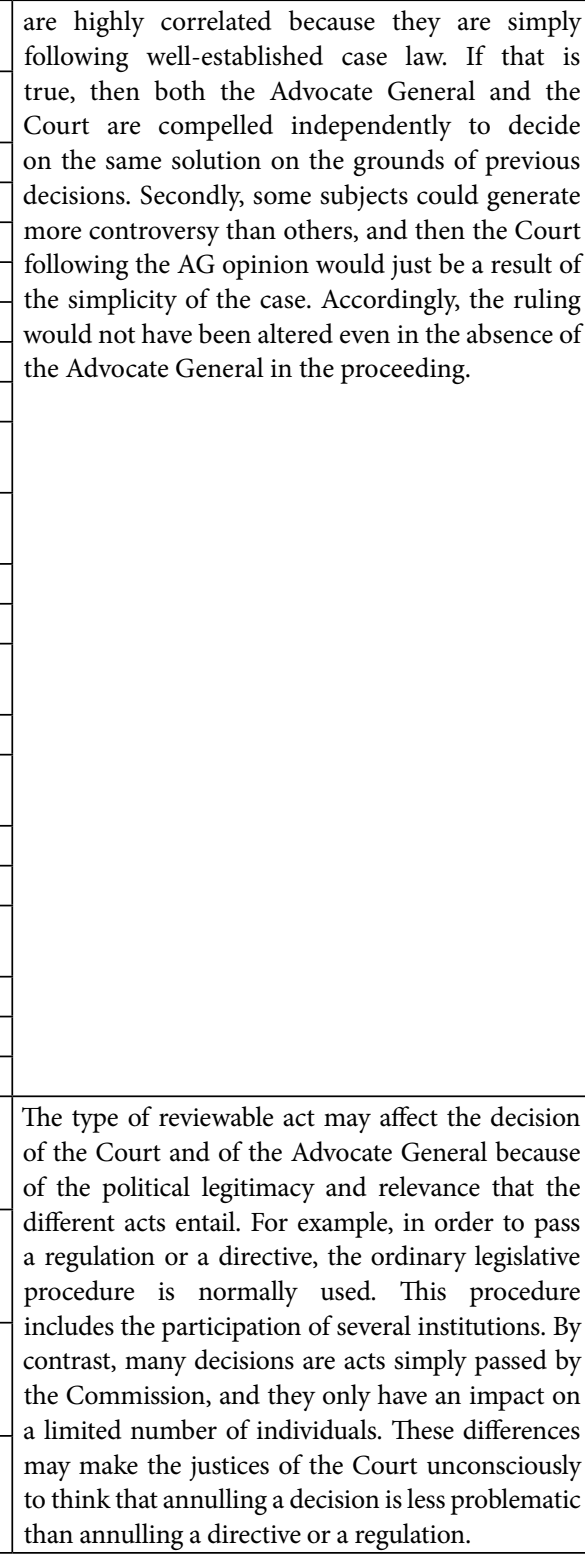 } \\
\hline & Directive & \\
\hline & Decision & \\
\hline & Other & \\
\hline
\end{tabular}

69 This group of variables is formed by four binary variables that take the value 1 if the legal act under review is that indicated on the name of the variable, and 0 otherwise. See TFEU (n 1) art 263 in combination with art 288 to understand which acts are reviewable in actions for annulment. 
Finally, the reader should bear in mind that, although we have carefully thought of which variables affect the outcome of actions for annulment and have included all the variables we could objectively extract from the database, it is not possible to include all of them. For example, we have not considered many psychological or sociological aspects that may affect judges in their decision-making. ${ }^{70}$ In that sense, our analysis has limitations. We acknowledge them, and draw our conclusions cautiously. Nevertheless, this study has taken an innovative approach that sheds some light on our research question and helps expand the academic literature in this topic.

\subsection{Probit regression}

In this study, we have used a type of regression that is well suited to capture the behaviour of binary dependent variables: the probit model. The probit model is a regression that explains the predicted probability of the dependent variable adopting the value 1 . In our case, it outputs the predicted probability of the Court annulling an act, subject to the value given to the other variables included. Therefore, the probit model provides a simple way to interpret the results in terms of predicted probability from 0 to 1 . Instead, if we had chosen a linear regression model, the result would not be enclosed between 0 and 1, making the interpretation impossible, as it could yield some predicted probabilities to be negative or above the unit.

Another possibility would be to use a logistic model. The logistic model likewise approximates a cumulative distribution function and allows an easy interpretation as well. It is beyond the scope of this article to determine which of the two-probit or logit models-is more suitable. The choice of using the probit model does not alter the results. Nevertheless, we have also estimated a linear regression and the logistic equivalent. ${ }^{71}$ For these alternative models, only negligible differences were observed on the estimated marginal effects of the variable of interest. Therefore, we proceed to explain our results based on six probit regressions estimated using the software, STATA.

\section{Results}

This section presents the results of six probit models created with STATA using the data collected over 20 years of actions for annulment before the Court of

71 Available upon request. 
Justice. First, we explain the different regressions created, in order to explore the behaviour of the Court on actions for annulment and the accuracy of the results that these regressions offer. Second, three different measures of the influence of the AG opinions on the Court's decisions are shown, looking at the effect of the variable AGannulment on ECJannulment. These measures are: (i) the coefficient of AGannulment; (ii) the marginal effect at means of AGannulment on ECJannulment; and (iii) the average marginal effect of AGannulment on ECJannulment. Finally, this section describes the influence of other variables on the behaviour of the Court of Justice. Table 2 below summarises the results.

\subsection{Accuracy of the estimated probit models}

In order to establish the influence of AGannulment on ECJannulment, we have considered six probit models (models 1-6 presented in the columns in Table 2). In all the models, the dependent variable is ECJannulment. The independent variables vary from model 1 that only includes the covariate of interest in this study (AGannulment) to models 2-6 that progressively add one more group of variables. ${ }^{72}$ Thus, model 2 includes AGannulment and the group of variables Claimant. Model 3 considers AGannulment and the blocks of variables Claimant and Advocate General. Model 4 incorporates AGannulment and the blocks of variables Claimant, Advocate General and Composition of the Court of Justice. Model 5 includes AGannulment and the group of variables Claimant, Advocate General, Composition of the Court of Justice and Subject-Matter. Finally, model 6 considers AGannulment and the groups of variables Claimant, Advocate General, Composition of the Court of Justice, Subject-Matter and Reviewable Act.

All of these models are an improvement on its predecessor, according to the information provided by the pseudo R-squared available in the last row of Table 2. We can observe the pseudo R-squared increase as we move columns towards the right. This means that model 2 explains ECJannulment more accurately than model 1 , model 3 more accurately than models 2 and 1 , and so forth. Therefore, model 6 is our most accurate estimate of the behaviour of the Court of Justice. In other words, more of the variation on the behaviour of the Court is explained as we add blocks of variables. The most accurate model (model 6) shows a pseudo 
R-squared of 50.2 per cent. This means that 50.2 per cent of the variation observed on the dependent variables (ECJannulment) is explained by the covariates included on this model. If the new blocks were adding noise to the simple model (model 1), we would not observe a solid pattern of increase on the explanatory power of our models. Moreover, had those variables been spurious to the relationship examined, the significance of our covariate of interest could have faded. Consequently, we can conclude that the decision to add more variables was adequate.

Furthermore, the command estat classification in STATA provides another method to test the accuracy of regressions with binary dependent variables. This command runs the model for each one of the cases provided in the sample to create the model. In this way, the model produces a predicted outcome for each observation. As the actual value for the dependent variable in the sample is known, prediction and reality can be compared. In our case, we have run the estat classification command for model 6 . Therefore, for each action for annulment considered in our sample, STATA inputs all the information it has about AGannulment and the groups of variables Claimant, Advocate General, Composition of the Court of Justice, Subject-Matter and Reviewable Act. It then gives a predicted probability of the Court actually annulling the act. Predicted probabilities above 0.5 are considered as predicting annulment (ECJannulment $=1$ ), while those below 0.5 are deemed dismissal (ECJannulment $=0$ ). Using this benchmark, we can calculate the percentage of the outcomes of cases correctly predicted for model 6 . For our sample, we found out that model 6 predicts 81 per cent of the outcomes of the cases correctly. Only 19 per cent are misclassified.

Finally, there is another indicator that strengthens the confidence in our model. This is a comparison of the sample mean of the outcome variable with the mean of the predicted probability for ECJannulment in model 6. In this study, these two measures are almost identical: 0.35 for the sample and 0.36 for the prediction.

In sum, model 6 seems to provide a reliable prediction of the behaviour of the Court of Justice in actions for annulment. Having asserted the general validity of our approach, the following sections explain the results obtained as regards the influence of the AG opinion on the Court of Justice.

\subsection{Measuring the influence of AGannulment on ECJannulment}

To measure the influence of the AG opinions on the decisions of the Court of Justice, we now look at: (i) the coefficient of AGannulment; (ii) the marginal effect at means of AGannulment on ECJannulment with all other variables at their means; 
and (iii) the average marginal effect of AGannulment on ECJannulment. All the results obtained for these three measures are significant at a level of 1 per cent.

\subsubsection{Coefficient of the variable AGannulment}

The first row in Table 2 shows the coefficients of the covariate of interest (AGannulment) for the six probit models. The coefficient of a variable in a probit model represents the change in the $\mathrm{z}$-value of the cumulative normal distribution. ${ }^{73}$ The only conclusion that we can draw from the value of the coefficient of a variable of a probit model is whether that variable makes a particular outcome on the dependent variable more or less likely. In this study, since the six columns show positive magnitudes, we can state that when an Advocate General recommends either total or partial annulment it is more likely that the Court of Justice adopts such an outcome in its decision.

\subsubsection{Marginal effect at means of AGannulment on ECJannulment}

The second row provides a more comprehensive way to interpret the coefficients than in the previous row. It shows the marginal effect at means of AGannulment, which is the method that is widely used to provide intuitive interpretations for the results obtained from probit models. ${ }^{74}$ To compute it, STATA first predicts the probability when AGannulment equals 1 and sets the other covariates at their sample means values. The software then does the same operation giving AGannulment the value of 0 . Subtracting these probabilities yields the marginal effect at means. This process gives us a number between 0 and 1 for each independent variable. That number shows the increase in the probability of ECJannulment annulling the act (ECJannulment $=1$ ) if the independent variable changes. Thus, for AGannulment, it shows the increase in the probability of the Court of Justice annulling the act if the Advocate General changes its opinion from dismissal to annulment, as long as the other variables that affect ECJannulment remain constant.

Accordingly, the marginal effect at means of AGannulment in model 6 indicates that when the Advocate General recommends the annulment of an act, Watson, Introduction to Econometrics (3rd edn, Prentice Hall 2010).

74 Richard Williams, 'Using the Margins Command to Estimate and Interpret Adjusted Predictions and Marginal Effects' (2012) 12 Stata J 308, 323-24. 
the Court is almost 80 per cent more likely to annul the act than if the Advocate General had not proposed its annulment. ${ }^{75}$ We also observe that the inclusion of new variables increases the magnitude of the marginal effect without damaging its significance. ${ }^{76}$ From model 1 to model 6 the marginal effect changes from 67 per cent to almost 80 per cent. This trend might suggest that our simplest model only represents correlation, and it does not show a causal link between the Court and the Advocate General because it is omitting variables.

However, according to Williams, some scholars prefer not to use this method of calculating marginal effects for probit models in which all the dependent variables are dichotomous, like the ones in our study. ${ }^{77}$ This is because inputting the sample means (which is a value between 0 and 1 ) in binary variables could be an arbitrary solution, since there is obviously no observation taking this specific value (since they can only take the value of either 0 or 1 ). ${ }^{78}$ Consequently, the use of the average marginal effect measure is preferred. ${ }^{79}$

\subsubsection{Average marginal effect of AGannulment on ECJannulment}

The average marginal effect (AME), instead of inputting the sample mean for the covariates, uses each of the actual values for each observation to find the marginal effect of AGannulment on that observation; then, it makes the average of the marginal effects of all the observations. ${ }^{80}$ For all our six models, the AME is robustly around 67 per cent. This means that, when the Advocate General recommends annulment, the Court is 67 per cent more likely to annul. This result contrasts with that of marginal effects at means in two aspects. First, it yields different numbers of what the marginal effect is. Although in other studies this methodological alternative does not produce different results to marginal effects at means, the change matters for our setting. ${ }^{81}$ Bartus points out the underlying mathematical

See the second row of column 6 in Table 2 .

See the second row in Table 2 . Note that the trend is similar to that in row 1.

Williams (n 74) 324.

ibid.

ibid.

ibid 325. The command used is 'margins, $\operatorname{dydx}\left({ }^{*}\right)$.

Marija Bockarjova and Mihails Hazans, 'Marginal Effects Distribution in Logit Models of Labour Markets' (Labour Markets, Work and Welfare during the Transition and Integration Processes Seminar, Vilnius, April 2000) <http://www.ibrarian.net/navon/page. jsp? paperid=279715\&searchTerm=marginal+models $>$ accessed 14 February 2015. 
reason for the different results we encounter between average marginal effects and marginal effects at means. ${ }^{82}$ According to the author, for marginal effects at means to provide an asymptotically valid approximation for average marginal effects several conditions must be satisfied. ${ }^{83}$ The models used in this study do not fulfil those conditions, and marginal effects at means are actually overestimating average marginal effects.

Second, the magnitude of the AME of AGannulment is similar for all six models. It can be said that the AME is robustly around 67 per cent. The lack of variation in the AME indicates that the blocks of variables progressively included are actually not causing omitted variable bias. They indeed improve the fit of the model, but they are not affecting our measure of the influence of the Advocate General. Conversely, analysing the marginal effects at means, we conclude that the measure increased from 67 per cent to around 80 per cent. This indicates the opposite, ie, it suggests that there is a downwards bias, and that the influence of the Advocate General is actually larger than a measure of correlation is able to prove.

For the purpose of this article, we are proceeding with the most cautious of our results: that of the average marginal effects. In short, we conclude that when the Advocate General proposes the annulment of an act in its opinion, the Court of Justice is around 67 per cent more likely to decide to annul the act or part of it.

\subsection{Influence of other variables on ECJannulment}

Finally, our results show that other variables influence the Court of Justice at a significant level. As one sees in Table 2, these are the variables: Advocate General Darmon and Grand Chamber. Advocate General Darmon is a significant variable consistently across all the models in which it is accounted for. It captures the presence of this Advocate General in a case, and shows that when he was present in a case, the Court was around 50 per cent more likely to annul the challenged act than if he was not present. ${ }^{84}$ Moreover, our results in models 4 and 6 show that the Court of Justice is 20 per cent less likely to annul the act if it is sitting in a Grand Chamber formation than if it sits in any other type of formation. ${ }^{85}$

85 This also refers to the average marginal effects. 


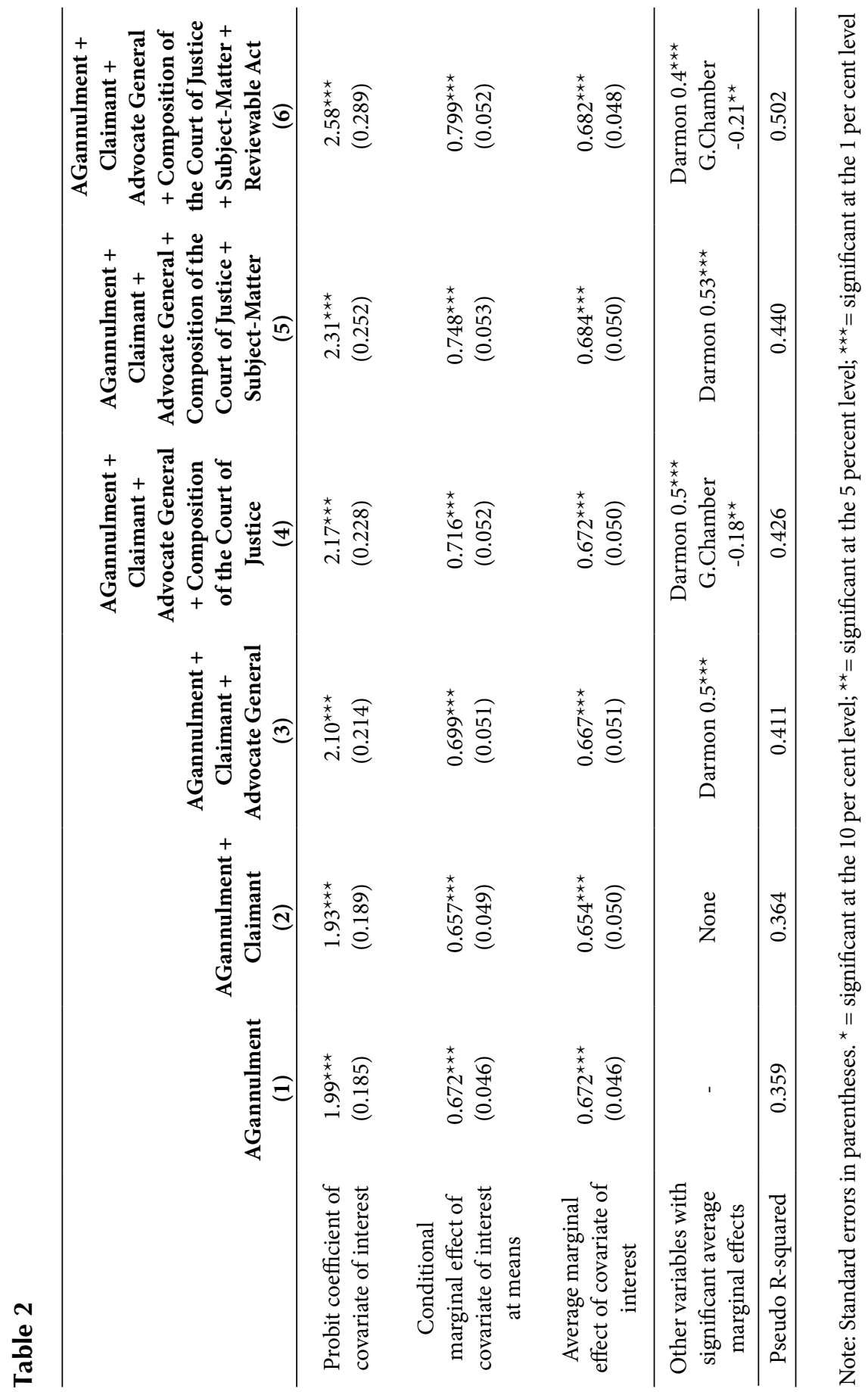




\section{Discussion}

In the previous section, we have shown that for our estimated regressions the AG opinions exert an influence on the Court of Justice, so that in actions for annulment the Court is more likely to annul an act if the Advocate General has suggested it. In particular, the average marginal effects measure for our sample suggests that the Court is approximately 67 per cent more likely to annul an act (or part of it) if the Advocate General advises to annul than if it advises to dismiss the case or declare it inadmissible.

We acknowledge that this measure is not a perfect representation of causality, because many elements may be missing from the quantitative analysis that was carried out of the relationship between the Advocate General and the Court. Furthermore, future research could expand this sample further than 20 years, or include different variables, to check if the results are still valid. Nevertheless, we consider that we have improved the measures offered in the existing literature by applying a more refined methodology, and building on econometric studies that used the AG opinion as a control variable for its measurement. ${ }^{86}$

Given the results of this research, it is difficult to reject the proposition that the Advocate General exerts some influence on the Court. Our results have been consistently significant for the variable AGannulment, and they have always shown a positive relationship between the Court and AGannulment. The addition of new variables does not eliminate this pattern, and highlights that AGannulment is the most influential of the significant variables. Furthermore, the accuracy of the regressions seems to increase as we add variables. Therefore, we believe that, even if the number of 67 per cent of increased probability is called into question, it is difficult to deny that there is some level of influence. In our methodology, we have defined the term influence as the ability to alter the decision of the Court, everything else remaining constant. For that reason, our results make it difficult to support attempts to underestimate what influence means, such as that of Advocate General Léger, who wrote:

The Advocate General is impartial, independent, influential, yet at no point does the AG usurp the most fundamental judicial prerogative of deciding cases. No matter how eloquent, how persuasive an Opinion may be, it may be disregarded for, after all, Judges are grown-ups capable of making up their own minds. ${ }^{87}$ 
Despite judges being adults who are free to choose and reason independently, our analysis shows that there is some component in the making of a decision that is simply attributed to what the Advocate General recommended.

This section discusses the implications that this conclusion may have in several on-going debates in the literature. We will briefly point out the potential consequences for two issues: judicial independence and the role of the Advocate General. The aim is not to suggest any solutions to these issues, but simply to foster the debate and provide it with new elements for discussion. These topics merit a thorough consideration, which is not within the scope of this article. As such, they are interesting topics for future research. Moreover, there may be other implications of our results that we have not yet identified.

\subsection{Judicial independence}

Judicial independence is a debated concept. ${ }^{88}$ Different definitions of the concept may lead to different aspects from which a court ought to be independent. ${ }^{89} \mathrm{~A}$ common understanding is one that defines independence as the separation of powers. ${ }^{90}$ In that sense, the judiciary has to be independent from the executive and the legislative powers, but not necessarily from internal elements within the judiciary. ${ }^{91}$ Per this definition, judicial independence is not necessarily put into jeopardy simply because the Advocate General influences the Court. The Advocate General is considered a full member of the Court of Justice of the European Union. ${ }^{92}$ As such, it would be expected to exert some influence on the outcome of cases.

One of the elements that allow the preservation of the independence of the Court is the secrecy of the deliberations. ${ }^{93}$ Member States do not know which judge(s) supported which arguments within a judgment. Thus, when judges Burbank (ed), Judicial Independence at the Crossroads: An Interdisciplinary Approach (SAGE 2002).

89 ibid 48.

90 ibid 46-47.

91 ibid 48.

92 See, eg, Craig and De Búrca (n 64) 62, for the common interpretation that the Advocate General is a full member of the Court of Justice based on TEU (n 1) art 19(2); TFEU (n 1) arts 252-53; CJEU Statute (n 3) art 8.

93 CJEU Statute (n 3) arts 2, 35; see Mark A Pollack, 'The New EU Legal History: What's New, What's Missing?' (2013) 28 American U Intl L Rev 1257, 1285. 
perform their duties, they will not be thinking about pleasing Member States in order to get re-elected in subsequent terms. In contrast, Advocates General are much more exposed. ${ }^{94}$ Their opinions are given in their personal capacity, and Member States can monitor their reasoned submissions. ${ }^{95}$ It could be argued that this might taint the impartiality of Advocates General that seek to be reappointed or have professional aspirations that depend on their governments. ${ }^{96} \mathrm{In}$ fact, Carrubba and Gabel have highlighted the fact that the 'institutional setting does not fully insulate the AG from potential political pressure, ${ }^{, 97}$ and found that the governments of the Member States can, in some cases, influence their Advocates General. ${ }^{98}$ By contrast, previous to that study, most authors seem to be confident about the many institutional checks and balances that help to ensure the independence of Advocates General. ${ }^{99}$

If the claim that Member States influence the AG opinions were proven valid, and we have asserted that these in turn influence the Court, one might question whether and to what extent that affects the independence of the Court itself. The conclusion that the AG opinion influences the judgments of the Court of Justice could mean that its own independence is linked to some extent with that of the entire Court of Justice of the European Union. More studies on this topic would be welcome to bring some clarity to the issue of judicial independence. ${ }^{100}$ If it were confirmed that judicial independence is at risk, the following aspects might

94 Carrubba and Gabel (n 6) 89.

95 ibid.

96 ibid.

97 ibid 95 .

98 ibid 89, 95-97, 112-13, 120.

99 For example: Borgsmidt (n 10) 107, 119; L Neville Brown and Tom Kennedy, The Court of Justice of the European Communities (5th edn, Sweet \& Maxwell 2000) 71; Burrows and Greaves (n 10) 4-7, 23, 49; Albors-Llorens (n 14) 512-13.

100 Such studies could build on the work of Carrubba and Gabel (n 6) 86-124; future research could also build on the studies that try to explain how Member States (and other actors) directly influence the Court of Justice via, inter alia, their observations. See, for instance, Lisa Conant, 'Review Article: The Politics of Legal Integration' (2007) 45 J Common Market Studies 45; Alec Stone Sweet and Thomas Brunell, 'The European Court of Justice, State Noncompliance, and the Politics of Override' (2012) 106 American Political Science Rev 204; Carrubba, Gabel and Hankla (n 6); Clifford J Carruba, Matthew Gabel and Charles Hankla, 'Understanding the Role of the European Court of Justice in European Integration' (2012) 106 American Political Science Rev 214; Daniel Naurin and others, 'Coding Observations of the Member States and Judgments of the Court of Justice of the EU under the Preliminary Reference Procedure 19972008' [2013] Centre for European Research (CERGU) Working Paper No 1, 2 <http://cergu. gu.se/digitalAssets/1438/1438554_2013-1.pdf> accessed 2 March 2015. 
need to be reconsidered: (i) the way in which the AG opinions are issued; (ii) the procedure of the Advocates General election and possible re-election; and (iii) the implications of the European Convention on Human Rights and the Charter of Fundamental Rights on the lack of judicial independence. ${ }^{101}$

\subsection{The role of the Advocate General}

There is much discussion about the role of the Advocate General. ${ }^{102}$ Many reasons have been put forward to explain the value of having a figure of this type in the Court of Justice. Some argue that it is valuable to have the AG opinion because the judgments of the Court do not provide enough details of the legal reasoning behind a decision. ${ }^{103}$ Differently, the AG opinion is generally more detailed and can be complementary to understanding the legal questions at stake in a specific case and the case law. ${ }^{104}$ Another suggestion is that the AG opinion may give an alternative interpretation of the law, which may be useful for future reference. ${ }^{105}$ Others also suggest that the Advocate General can be viewed as some sort of first instance with a compulsory appeal. ${ }^{106}$

The way in which our results impact this debate is not clear. These points may still be valid, even if there is a relationship of influence between the Court and the Advocate General. Potentially, the above statements could be tested in future quantitative research. For example, an analysis of the kind that was conducted in this article could be replicated for the General Court to find out the influence of its judgments on appeal cases decided by the Court of Justice. This would allow

101 Convention for the Protection of Human Rights and Fundamental Freedoms (adopted 4 November 1950, entered into force 3 September 1953, amended by Protocols Nos 3, 5, 8 and 11) 213 UNTS 222 (European Convention on Human Rights); Charter of Fundamental Rights of the European Union [2000] OJ C364/01. We are grateful to the participants at the DurhamCambridge Doctoral Workshop in EU Law-'Igniting European Union Law: Frameworks for the Future' for raising these issues.

102 See the literature cited in Section 2 above.

103 For example, Vranken (n 10) 39; Albors-Llorens (n 14) 510; Hinarejos (n 39) 625.

104 ibid.

105 Ritter (n 4) 763; on the idea that the AG opinion could be thought of as a 'dissenting opinion', see Julia Laffranque, 'Dissenting Opinion in the European Court of Justice-Estonia's Possible Contribution to the Democratisation of the European Union Judicial System' (2004) IX Juridica Intl 14, 18-19.

106 Borgsmidt (n 10) 107; Dashwood (n 4) 213. 
comparing the influence of the General Court with that of the Advocate General in the decisions of the Court of Justice.

\section{Conclusion}

This article examines the existing literature on the influence of the Advocate General on the Court of Justice. Aiming to overcome shortcomings found in the literature and building on relevant studies in circumfluent topics, we conducted an econometric analysis, designing a probit model to quantitatively measure the influence of the AG opinions in the decisions of the Court of Justice. Our conclusion is that the Court of Justice is approximately 67 per cent more likely to annul an act (or part of it) if the Advocate General advises the Court to annul than if it advises the Court to dismiss the case or declare it inadmissible. Finally, this article briefly discusses the implications that this conclusion may have in several on-going debates in the literature-namely, judicial independence and the role of the Advocate General. We hope to have contributed to the better understanding of the influence of the Advocate General on the Court of Justice and to a more informed debate on the role and future of the figure of the Advocate General. This article hopes to foster further research in this topic, which ultimately may reveal the need for judicial reform. 